\title{
Tick-borne diseases of bovines in Pakistan: major scope for future research and improved control
}

\author{
Abdul Jabbar ${ }^{1 *}$, Tariq Abbas ${ }^{2}$, Zia-ud-Din Sandhu ${ }^{3}$, Hafiz A Saddiqi ${ }^{4}$, Muhammad F Qamar ${ }^{5}$ and Robin B Gasser ${ }^{1}$
}

\begin{abstract}
Ticks and tick-borne diseases (TBDs) affect the productivity of bovines in tropical and subtropical regions of the world, leading to a significant adverse impact on the livelihoods of resource-poor farming communities. Globally, four main TBDs, namely anaplasmosis, babesiosis, theileriosis, and cowdriosis (heartwater) affect bovines, and the former three are of major economic importance in bovines in Pakistan. Given that the livestock sector has become an integral part of Pakistan's economy and a large number of dairy cattle are being imported into the country, in order to meet an increasing demand of milk and milk products, it is timely to review current status of bovine TBDs in Pakistan and to identify gaps in the knowledge of TBDs and their control. Although there has been a recent increase in the number of studies of TBDs in this country, information on their prevalence, distribution, tick vectors, and control is limited. This article provides a brief background on key bovine TBDs and ticks and reviews the current status of bovine TBDs in Pakistan to identify gaps in knowledge and understanding of these diseases, propose areas for future research and draw attention to the need for improved tools for the diagnosis and control of TBDs in this country.
\end{abstract}

Keywords: Tick-borne diseases, Theileria, Babesia, Anaplasma, Cattle, Water buffalo, Pakistan

\section{Introduction}

Livestock plays a pivotal role in Pakistan's economy by uplifting the socioeconomic conditions of resource-poor farming communities and alleviating poverty. The livestock sector in Pakistan is represented mainly by small farm holders to meet the needs of nutrients and proteins, food security, and income. In the financial year 2013/2014, the livestock sector contributed $11.8 \%$ to the Gross Domestic Product (GDP) of Pakistan; its share in the value of all agricultural commodities was $55.9 \%$ [1]. In the livestock sector, water buffaloes, and cattle with an estimated population size of 35-40 million, are the main milk-producing animals, and yielding approximately 18,000-31,000 million tons of milk [1]. Based on location and herd size, dairies in Pakistan are classified into four systems, including smallholder subsistence (milk produced to meet household needs), smallholder market-oriented (milk produced for home use with small, but regular surpluses for sale); rural commercial (larger herds of $>40$ animals, well organised, with direct

\footnotetext{
* Correspondence: jabbara@unimelb.edu.au

${ }^{1}$ Faculty of Veterinary and Agricultural Sciences, The University of Melbourne, Werribee, Victoria, Australia

Full list of author information is available at the end of the article
}

links to milk processing plants); and peri-urban (gowalas; animal husbandrists in the outskirts of cities, with herd size of $\sim 20$ animals, selling into urban areas) [2,3].

Based on climate, water availability, land use, and physiography, Pakistan is divided into ten agro-ecological zones, which influence temporal, and spatial patterns of livestock diseases. Being located in a subtropical zone $\left(30^{\circ} \mathrm{N}, 70^{\circ} \mathrm{E}\right)$ within South Asia, most parts of Pakistan offer favourable environmental conditions for ticks, which can infest a variety of hosts and transmit diseases to humans, livestock, and companion animals. Ticks and tick-borne diseases (TBDs) cause substantial economic losses in bovines, particularly in tropical, and subtropical regions, where $80 \%$ of the world's total cattle population occurs [4], and can significantly affect the livelihoods of resource-poor farming communities due to lower productivity of both beef and dairy cattle in these regions $[5,6]$.

Theileriosis (caused by Theileria annulata), babesiosis (Babesia bovis, B. bigemina, and B. divergens) and anaplasmosis (Anaplasma marginale and A. centrale) have been reported to affect both water buffaloes (Bubalus bubalis) and cattle (Bos indicus and Bos taurus) in Pakistan [7-9]. Given the relatively rapid expansion of the dairy industry and the increased importation of high 
milk-producing dairy cattle (e.g., Holstein, and Friesian) from overseas countries to replace and/or improve indigenous local breeds of cattle, it has become crucial to assess the status of TBDs in indigenous and exotic breeds of cattle and water buffaloes, as exotic breeds are usually highly susceptible to TBDs [10]. The purpose of this article is (i) to provide a brief background on key bovine TBDs and ticks, (ii) to review the current state of knowledge of bovine TBDs in Pakistan, (iii) to identify gaps in the knowledge and understanding of these diseases, and (iv) to propose areas for future research, focusing on developing improved approaches for their diagnosis and control in this country.

\section{Background on TBDs and tick vectors relevant to the context in Pakistan}

Principal bovine TBDs, the main pathogens involved, their distribution, and tick vectors are given in Table 1. In addition, the status of these diseases and ticks in their transmission in Pakistan are listed. The following section provides an account of the three key bovine TBDs in Pakistan.

\section{Theileriosis}

Theileriosis is a disease caused by intracellular protozoan parasites of the genus Theileria (Apicomplexa: Piroplasmida; Theileriidae), transmitted by ixodid ticks. Usually, the geographical distribution of Theileria species is restricted to tropical and subtropical regions, where suitable tick vectors occur. Theileria species infect primarily wild and domestic ruminants, and cause economically significant diseases in cattle, sheep, and goats. For instance, T. annulata, and T. parva (the causative agents of tropical or Mediterranean and East Coast Fevers, respectively) are known to be the most pathogenic species in bovines, whereas other species, such as $T$. mutans, $T$. taurotragi, and members of the T. orientalis complex, often cause asymptomatic infections in this host group [11-13]. Depending on the type of theileriosis, a number of hard ticks belonging to the genera Amblyomma, Haemaphysalis, Hyalomma, and Rhipicephalus can transmit theilerioses (see Table 1) [14]. T. annulata causes a severe, potentially fatal disease in cattle, leading to significant economic losses in endemic countries in Africa and Asia, and is mainly transmitted by ticks of the genus Hyalomma [14]. In general, tropical theileriosis is more severe in exotic and cross-bred cattle (Bos taurus) than indigenous animals (e.g., Bos indicus) [10]. For example, the disease became significant in India when a program was launched to increase milk production by introducing exotic breeds. Mostly, the disease occurs in its subclinical form, leading to significant economic losses; without treatment or control, case fatality rates can reach $80 \%$ in exotic breeds, compared with $\sim 20 \%$ in indigenous breeds $[15,16]$. Major clinical signs include pyrexia, enlargement of lymph nodes, particularly of those draining the site of attachment of ticks, tachycardia, tachypnea, nasal discharge, loss of weight, and condition, severe pulmonary distress due to oedema, and death in severe cases [14]. Tropical theileriosis can be treated with the specific anti-Theileria drugs, such as buparvaquone, and parvaquone [14].

\section{Babesiosis}

Babesiosis, caused by infection with intraerythrocytic protozoan parasites of the genus Babesia (Apicomplexa: Piroplasmida: Babesiidae), is one of the commonest infections of animals worldwide. In recent years, the disease has been gaining interest in human medicine due to emerging zoonotic infections [17]. Bovine babesioses can be caused by a number of Babesia species, but $B$. bovis, B. bigemina, and $B$. divergens are the most important species, both economically, and clinically, in both water buffaloes and cattle (see Table 1). These diseases occur in temperate, subtropical, and tropical regions of the world and affect more than a billion cattle globally [18]. Depending on the form of babesiosis, species of Rhipicephalus, and Ixodes are involved in the transmission to bovines (see Table 1) [18]. B. bovis is considered to be the most pathogenic species, followed by $B$. bigemina, and $B$. divergens [18]. The former two species of Babesia occur in the tropics and subtropics, whereas the latter is prevalent in Europe and also of zoonotic importance [18]. Clinical signs depend on virulence and pathogenic effects of a particular Babesia species, and host factors associated with disease include age, breed, and immune status [18]. Major signs include high fever, depression, anorexia, haemoglobinaemia, haemoglobinuria, icterus, abortion in pregnant cows, and death in severe cases [18]. B. bovis infection can also cause nervous and respiratory symptoms due to the sequestration and effects of infected erythrocytes in the capillary beds of vital internal organs [19]. For treatment and prophylaxis of bovine babesiosis, diminazine, and imidocarb are the only two drugs available [18].

\section{Anaplasmosis}

Anaplasmosis is a disease of domestic and wild ruminants, caused by obligate intraerythrocytic rickettsiae of the genus Anaplasma (Rickettsiales: Anaplasmatacea), and is distributed in tropical and subtropical regions of the world. In bovines, anaplasmosis is caused mainly by $A$. marginale and, to a lesser extent, by $A$. centrale. The disease is usually transmitted by ticks, but it can also be transmitted mechanically by biting flies or contaminated surgical instruments and/or needles [20]. Almost 20 tick species have been shown to transmit anaplasmosis experimentally [21], and the most important tick genera 
Table 1 Major tick-borne diseases (TBDs) of bovines: principal pathogens, principal hosts, principal vectors, and distribution. Current status of the main bovine TBDs and potential vectors in Pakistan are also provided.

\begin{tabular}{|c|c|c|c|c|c|c|}
\hline $\begin{array}{l}\text { Tick-borne disease } \\
\text { (TBDs) }\end{array}$ & Principal pathogens & Principal host (s) & Principal ticks vectors & Distribution & $\begin{array}{l}\text { Bovine TBDs reported } \\
\text { from Pakistan }\end{array}$ & $\begin{array}{l}\text { Possible tick vectors in } \\
\text { Pakistan }\end{array}$ \\
\hline \multirow[t]{9}{*}{ Theileriosis } & \multirow[t]{4}{*}{ Theileria annulata } & \multirow[t]{4}{*}{ Cattle, Asian buffalo } & Hyalomma detritum detritum & \multirow{4}{*}{$\begin{array}{l}\text { Southern Europe, North Africa, } \\
\text { Middle East, Sudan, central Asia, } \\
\text { and Indian subcontinent, }\end{array}$} & \multirow[t]{4}{*}{ Yes } & \multirow[t]{2}{*}{ H. anatolicum anatolicum, } \\
\hline & & & H. anatolicum & & & \\
\hline & & & H. dromedarii & & & H. dromedarii, \\
\hline & & & H. lusitanicum & & & H. marginatum marginatum \\
\hline & T. parva & Cattle, African buffalo & $\begin{array}{l}\text { Rhipicephalus appendiculatus, } \\
\text { R. zambeziensis }\end{array}$ & $\begin{array}{l}\text { Eastern, central and southern } \\
\text { parts of Africa }\end{array}$ & No & Not applicable (NA) \\
\hline & T. orientalis & Cattle, Asian buffalo & Haemaphysalis longicornis & Cosmopolitan & No & NA \\
\hline & T. mutans & Cattle, African buffalo & Amblyomma spp. & Sub-Saharan Africa & No & NA \\
\hline & T. velifera & Cattle, African buffalo & Amblyomma spp. & Sub-Saharan Africa & No & NA \\
\hline & T. taurotragi & Cattle, Eland antelope & R. appendiculatus & East and southern Africa & No & NA \\
\hline \multirow[t]{4}{*}{ Babesiosis } & Babesia bigemina & Cattle, buffalo & R. (B.) microplus & $\begin{array}{l}\text { Tropical and subtropical } \\
\text { regions }\end{array}$ & Yes & R. (B.) microplus \\
\hline & B. bovis & Cattle, buffalo & R. (B.) microplus & $\begin{array}{l}\text { Tropical and subtropical } \\
\text { regions }\end{array}$ & Yes & R. (B.) microplus \\
\hline & B. divergens & Cattle & Ixodes ricinus & Europe and North Africa & No & NA \\
\hline & B. orientalis & Buffalo & Rhipicephalus spp. & Asia & No & NA \\
\hline \multirow[t]{5}{*}{ Anaplasmosis } & \multirow[t]{2}{*}{ Anaplasma marginale } & \multirow[t]{2}{*}{ Cattle, domestic buffalo } & \multirow{2}{*}{$\begin{array}{l}\text { Rhipicephalus (Boophilus) microplus, } \\
\text { R. (B.) decoloratus, R. (B.) annulatus, } \\
\text { R. bursa, R. simus, R. evertsi }\end{array}$} & \multirow{2}{*}{$\begin{array}{l}\text { Tropical, subtropical and even } \\
\text { temperate regions }\end{array}$} & \multirow[t]{2}{*}{ Yes } & R. (B.) microplus \\
\hline & & & & & & Hyalomma spp. \\
\hline & A. centrale & Cattle & As above & $\begin{array}{l}\text { Tropical and subtropical } \\
\text { regions }\end{array}$ & Yes & As above \\
\hline & A. (Ehrlichia) bovis & Cattle, domestic buffalo & $\begin{array}{l}\text { Amblyomma spp., Hyalomma spp., } \\
\text { Rhipicephalus spp. }\end{array}$ & Africa, Asia, and South America & No & NA \\
\hline & $\begin{array}{l}\text { A. (Ehrlichia) } \\
\text { phagocytophilum }\end{array}$ & Cattle, small ruminants, horses & Ixodes spp. & Europe and North America & No & NA \\
\hline
\end{tabular}

aoonotic importance; Source: [7, 10, 18, 20, 29, 31] 
involved in the transmission of this disease are Hyalomma and Rhipicephalus species (see Table 1) [20]. Clinically, the disease is manifested in a number of forms, from subclinical to fatal, depending on the virulence of the species/ strain of Anaplasma, susceptibility of the host, or concurrent infections. Major clinical signs include pyrexia, progressive anaemia, jaundice, anorexia, depression, reduced milk production, abortion in pregnant animals, and death, particularly in exotic breeds [20]. Anaplasmosis is difficult if not impossible to differentiate clinically from theileriosis and babesiosis. Animals recovering from this disease usually develop an asymptomatic carrier status [20]. The treatment of bovine anaplasmosis includes the parenteral administration of tetracyclines (chlortetracycline and oxytetracycline) or imidocarb dipropionate [20].

\section{Economic significance of ticks and TBDs}

Ticks themselves also cause substantial economic losses in cattle by reducing productivity and fertility, and sometimes causing deaths [22]. Tick infestation reduces the productivity of cattle in a number of ways, including: (i) the direct effect of attachment and feeding ('tick worry'), (ii) the injection of toxins, (iii) hide damage due to their bites, (iv) a reduction in weight gain due to the sucking of blood by female, adult ticks (e.g., Rhipicephalus microplus), (v) reduced milk production, and quality, and (vi) morbidity and mortality associated with the diseases that they transmit $[6,23-26]$. Various studies have estimated losses caused by ticks and TBDs in cattle. For example, De Castro [4] estimated the global production economic losses caused by ticks and TBDs at about USD 14-19 billion per year. Recently, studies in Australia, and India have also estimated annual losses at USD 26 million [27] and 499 million [28], respectively.

\section{Current knowledge of bovine TBDs in Pakistan}

In Pakistan theileriosis, babesiosis, and anaplasmosis are major infectious diseases of water buffaloes and cattle, and are caused by T. annulata, B. bovis, and B. bigemina as well as $A$. marginale and $A$. centrale, respectively [7-9]. These diseases are transmitted by ixodid ticks, and a large number of these ticks infest water buffaloes and cattle in Pakistan, including species of Dermacentor, Haemaphysalis, Hyalomma, and Rhipicephalus [7, 29-33] (see Table 1). A number of species of Hyalomma and Rhipicephalus are considered to be the predominant vectors of bovine theileriosis and babesiosis, respectively [30]. To date, only one study has shown the role of Hyalomma spp. in the transmission of $T$. annulata by the molecular detection of the parasite in ticks [32] (see Table 2), whereas the role of other ticks in the transmission of other bovine TBDs in Pakistan remains to be explored. In the following sections, we reviewed the peer-reviewed scientific literature on bovine TBDs in Pakistan which were accessible on the 31st of March 2015 through CABI Abstracts, PubMed, and national scientific journals.

\section{Theileriosis}

The most studied bovine TBD in Pakistan is tropical theileriosis. To date, 16 studies have reported the prevalence of this disease (Table 2), with the majority of investigations being conducted in Punjab (number of districts studied $=19)$, followed by Khyber Pakhtunkhwa $(n=2)$ and Sindh $(n=2)$ provinces (Fig. 1; Table 2). In Pakistan, more studies of theileriosis have been undertaken in cattle $(n=13)$ than in water buffaloes $(n=6)$, and most of them investigated healthy animals located either on private dairy farms near the major veterinary research institutions or public livestock research stations (Table 2). Almost all of these studies used a convenient sampling strategy for the collection of blood samples, without defining criteria for the selection of a location or particular herds or number of animals to be tested, thus, likely leading to sampling bias and possible misrepresentation of the actual population in a district, an agro-ecological zone, or province. Using conventional diagnostic methods, the mean ( \pm standard error of mean) prevalence rates of theileriosis in water buffaloes and cattle reported for Pakistan are estimated at $10.6 \pm 3.5 \%$ (range from 0.98 to $38.3 \%$ ) and $2.65 \pm 0.9 \%(0.6-5.0 \%)$, respectively. However, higher prevalences were estimated when molecular diagnostic methods were used to test water buffaloes (34.5 $\pm 15.5 \%$; range 19.0-50.0 \%) and cattle (38.7 \pm 9.9 ; range from 19.0 to $66.1 \%)$ [32, 34-37]. As a number of Hyalomma species are known to transmit $T$. annulata, a single study has thus far identified $T$. annulata from $H$. anatolicum (prevalence: $50.0 \% ; 10 / 20$ ) and $H$. dromedarii (prevalence $20.0 \%$; 4/20) in Pakistan (Table 2, [32]). A number of risk factors have been predicted to be associated with tropical theileriosis in bovines in Pakistan. For example, Muhammad et al. [38] identified clinico-epidemiological factors to be associated with theileriosis in cross-bred cattle in Faisalabad and showed that young calves of cross-bred cattle were more susceptible to disease from February to November, with a disease peak occurring in June when tick activity was high.

\section{Babesiosis}

A total of 15 studies have reported bovine babesiosis from Pakistan, and most of them were conducted in Punjab (number of districts studied $=12$ ), followed by Khyber Pakhtunkhwa $(n=3)$ and Sindh $(n=2)$ provinces (Fig. 1; Table 3). The majority $(n=14)$ of these investigations focused on exotic and local breeds of cattle, whereas only four studied the disease in water buffaloes (see Table 3 ). The mean ( \pm standard error of mean) prevalence rates of babesiosis in water buffaloes and cattle reported for Pakistan are estimated at $7.5 \pm 1.5 \%$ 
Table 2 List of key studies of Theileria/theileriosis in Pakistan

\begin{tabular}{|c|c|c|c|c|c|c|c|}
\hline \multirow[t]{2}{*}{ Host (s) } & \multirow[t]{2}{*}{ Location (s) } & \multirow[t]{2}{*}{$\begin{array}{l}\text { Study population and sampling } \\
\text { design }\end{array}$} & \multirow[t]{2}{*}{ Sampling period } & \multirow[t]{2}{*}{$\begin{array}{l}\text { Detection } \\
\text { method (s) }\end{array}$} & \multicolumn{2}{|c|}{$\begin{array}{l}\text { Percentage of test positive } \\
\text { animals (proportion) }\end{array}$} & \multirow[t]{2}{*}{ Reference } \\
\hline & & & & & Cattle & Buffaloes & \\
\hline Cattle (Sahiwal x Holstein-Friesian) & Faisalabad & $\begin{array}{l}\text { Animals suspected of theileirosis } \\
\text { from the University farm }\end{array}$ & May-Jun 1982 & Blood smear & $100(3 / 3)$ & NA & [39] \\
\hline Buffaloes, cattle (local breeds) & Hyderabad & $\begin{array}{l}\text { Healthy animals from local private } \\
\text { dairy farms; convenient }\end{array}$ & Oct 1990 to Dec 1991 & Blood smear & $3(3 / 100)$ & $5(5 / 100)$ & {$[40]$} \\
\hline $\begin{array}{l}\text { Cattle (Jersey, Sahiwal, } \\
\text { Holstein-Friesian, cross-bred) }\end{array}$ & Faisalabad & $\begin{array}{l}\text { Animals suspected of theileriosis } \\
\text { from local private dairy farms; } \\
\text { convenient }\end{array}$ & Mar 1993 to Sep 1998 & $\begin{array}{l}\text { Clinical signs and } \\
\text { blood smear }\end{array}$ & $79.5(89 / 112)$ & NA & [38] \\
\hline $\begin{array}{l}\text { Buffaloes, cattle (local and } \\
\text { exotic breeds) }\end{array}$ & Attock, Islamabad & $\begin{array}{l}\text { Healthy animals were from public } \\
\text { livestock farms; convenient }\end{array}$ & Sep 1999 to May 2001 & Blood smear & $0.98(3 / 307)$ & $0.6(1 / 155)$ & [41] \\
\hline Cattle (local breeds) & Peshawar & $\begin{array}{l}\text { Healthy animals from local private } \\
\text { dairy farms; convenient }\end{array}$ & 2001 & Blood smear & $1.4(4 / 285)$ & NA & {$[42]$} \\
\hline \multirow[t]{2}{*}{ Cattle (Friesian and Jersey) } & \multirow[t]{2}{*}{ Kasur } & \multirow{2}{*}{$\begin{array}{l}\text { Healthy animals from a public } \\
\text { livestock farm; convenient }\end{array}$} & \multirow[t]{2}{*}{ Jul 2003 to Jun 2004} & \multirow[t]{2}{*}{ Blood smear } & Holstein: 24 (48/200) & NA & \multirow[t]{2}{*}{ [43] } \\
\hline & & & & & Jersey: 15 (30/200) & & \\
\hline Buffaloes & Lahore & $\begin{array}{l}\text { Animals suspected of theileriosis } \\
\text { from local private dairy farms; } \\
\text { convenient }\end{array}$ & Jul to Sep 2003 & Blood smear & NA & $17.5(107 / 600)$ & [44] \\
\hline \multirow[t]{2}{*}{ Friesian cattle } & \multirow[t]{2}{*}{ Kasur } & \multirow{2}{*}{$\begin{array}{l}\text { Healthy animals from local } \\
\text { private dairy farms; convenient }\end{array}$} & \multirow[t]{2}{*}{-} & Blood smear, & ${ }^{1} \mathrm{BS}: 14(14 / 100)$ & \multirow[t]{2}{*}{ NA } & \multirow[t]{2}{*}{ [7] } \\
\hline & & & & PCR & 2PCR: $36(36 / 100)$ & & \\
\hline Holstein-Friesian and Jersey cattle & Sahiwal & $\begin{array}{l}\text { Healthy animals from local private } \\
\text { dairy farms; convenient }\end{array}$ & Apr to Sep 2009 & Blood smear & $38.3(115 / 300)$ & NA & {$[45]$} \\
\hline \multirow[t]{2}{*}{ Buffaloes, cattle (local breeds) } & \multirow{2}{*}{$\begin{array}{l}\text { Bahawalnagar, Bhakar, } \\
\text { Layyah, Multan, Muzaffar } \\
\text { Garh, Vehari }\end{array}$} & \multirow{2}{*}{$\begin{array}{l}\text { Healthy animals from local private } \\
\text { dairy farms; convenient }\end{array}$} & \multirow[t]{2}{*}{-} & Blood smear, & \multirow{2}{*}{$\begin{array}{l}\text { BS: } 3 \text { (4/144); } \\
\text { PCR: } 19 \text { (28/144) }\end{array}$} & & \multirow[t]{2}{*}{ [37] } \\
\hline & & & & PCR & & & \\
\hline Buffaloes & Karachi & $\begin{array}{l}\text { Healthy animals from the Landhi } \\
\text { Dairy Colony; convenient }\end{array}$ & Apr to Oct 2011 & Blood smear & N/A & $2(2 / 100)$ & {$[46]$} \\
\hline \multirow[t]{2}{*}{ Cattle (local and exotic breeds) } & \multirow[t]{2}{*}{ Sargodha } & \multirow{2}{*}{$\begin{array}{l}\text { Healthy animals from local private } \\
\text { dairy farms; multi-stage cluster } \\
\text { random }\end{array}$} & \multirow[t]{2}{*}{ Aug 2008 to Jul 2009} & \multirow[t]{2}{*}{ Blood smear } & $6.7(24 / 350)$ & \multirow[t]{2}{*}{ N/A } & \multirow[t]{2}{*}{ [47] } \\
\hline & & & & & ${ }^{3}$ Mixed: 2.6 (9/350) & & \\
\hline Cattle (local and exotic breeds) & $\begin{array}{l}\text { Khushab, Rawalpindi, } \\
\text { Sargodha }\end{array}$ & $\begin{array}{l}\text { Healthy animals from local private } \\
\text { dairy farms; convenient }\end{array}$ & Sep 2009 to Aug 2010 & Blood smear & $5.14(54 / 1050)$ & N/A & [48] \\
\hline \multirow[t]{2}{*}{ Cattle (local breeds) } & \multirow[t]{2}{*}{ Kohat, Peshawar } & Healthy animals from local private & Nov 2010 to Feb 2011 & Blood smear, & BS: $5.3(5 / 95)$ & NA & {$[36]$} \\
\hline & & dairy farms; simple random & & $P C R$ & PCR: 33.7 (32/95) & & \\
\hline $\begin{array}{l}\text { Ticks (Hyalomma anatolicum, } \\
\text { Hyalomma dromedarii) }\end{array}$ & Faisalabad, Jhang, Khanewal & $\begin{array}{l}\text { Healthy animals from local private } \\
\text { dairy farms; convenient }\end{array}$ & Jul, Aug 2007 & PCR & $\begin{array}{l}{ }^{4} \mathrm{Ha}: 50(10 / 20), \\
{ }^{5} \mathrm{Hd}: 20(4 / 20)^{*}\end{array}$ & & [32] \\
\hline Buffaloes, cattle (Sahiwal breed) & Okara, Sheikhupura & $\begin{array}{l}\text { Healthy animals from local private } \\
\text { dairy farms; convenient }\end{array}$ & - & PCR & $66.1(41 / 62)$ & $50(20 / 40)$ & {$[35]$} \\
\hline
\end{tabular}

${ }^{1}$ Blood smear; ${ }^{2}$ Polymerase chain reaction; ${ }^{3}$ Mixed infection of T. annulata with either A. marginale or B. bigemina; ${ }^{4}$ Hyalomma anatolicum, ${ }^{5}$ Hyalomma dromedarii; ${ }^{*}$ host information was not provided; - denotes lack of information 


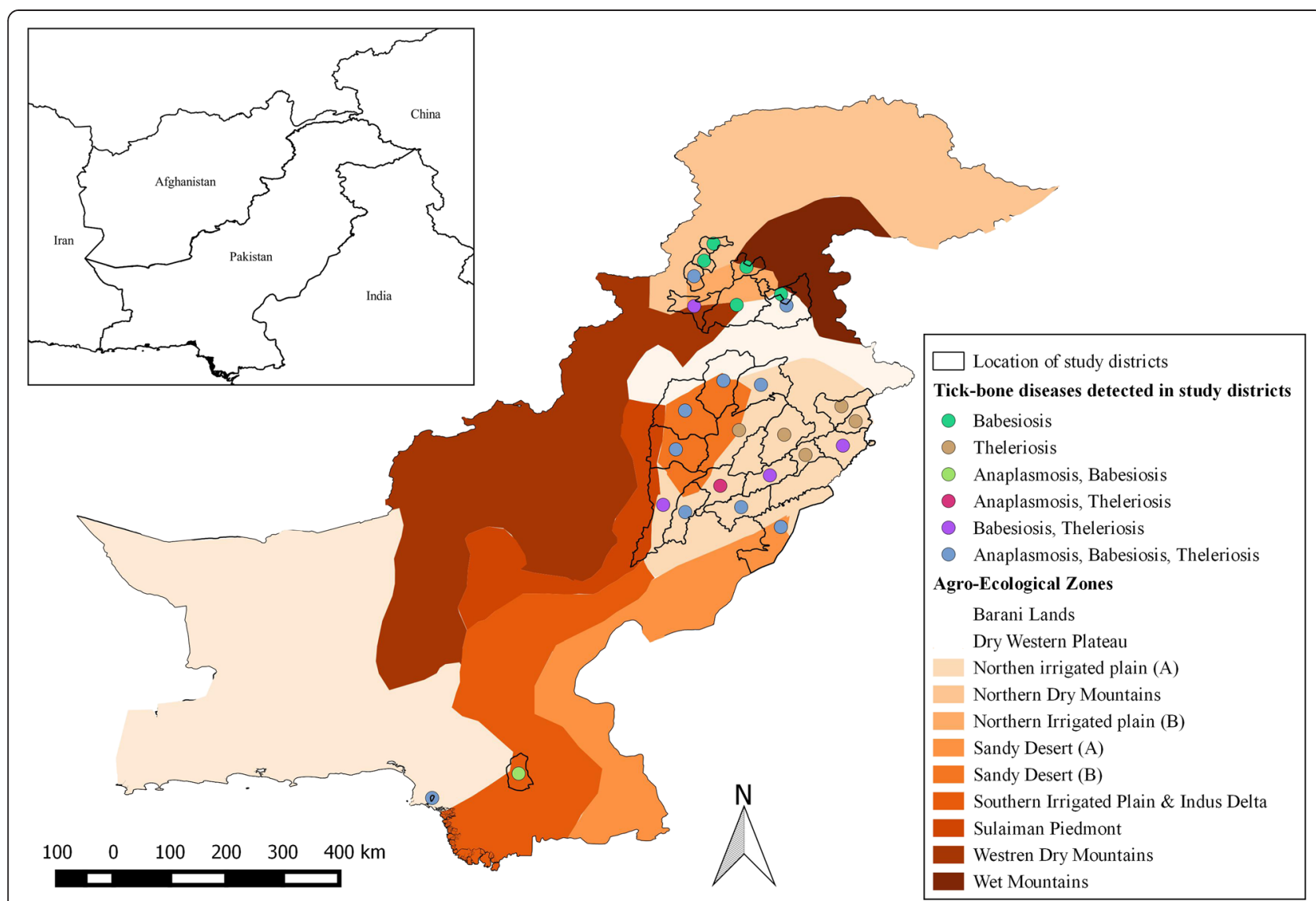

Fig. 1 Map of Pakistan showing districts where prevalence studies of tick-borne diseases (shown in circles of different colours) have been conducted. The distinct colours on the map indicate various agro-ecological zones of Pakistan. The inset map shows the neighbouring countries of Pakistan.

(range: $0.65-29.0 \%$ ) and $5.7 \pm 4.4 \%$ (range: $1.0-23.1 \%$ ), respectively. Using a traditional diagnostic method (i.e., stained blood smear), the prevalence of babesiosis was considerably lower (1-18 \%) than that obtained employing molecular diagnostic methods (up to $29 \%$ ) (Table 3; $[49,50])$. Bovine babesiosis mostly occurs in exotic (susceptible) breeds of cattle during the hot and humid months (July to September). Like theileriosis, the precise prevalence of babesiosis in Pakistan is unknown, as there seems to have been a sampling bias as a consequence of the selection of animals, locations, and agro-ecological zones investigated. Although $R$. microplus is the main vector of babesiosis worldwide, to date, there has been no study to assess the role of this tick, other vectors, or proposed mechanical means of disease transmission.

\section{Anaplasmosis}

In Pakistan, bovine anaplasmosis is mainly caused by $A$. marginale [56]; thus far, 12 studies have reported the disease in cattle (number of districts studied $=10$ ) and water buffaloes $(n=8)$ from the provinces Punjab (number of districts studied $=9)$, Khyber Pakhtunkhwa $(n=2)$ and Sindh $(n=2)$ (Fig. 1; Table 4). Based on conventional (i.e., stained blood smear) methods, the mean ( \pm standard error of mean) prevalence rates of anaplasmosis in water buffaloes and cattle in Pakistan are $19.2 \pm 4.7 \%$ (range: $3.1-60.0 \%$ ) and $13.2 \pm 3.7 \%$ (range: $4.3-60.0 \%$ ), respectively. Haider, and Bilqees [8] reported the highest $(60.0 \%)$ prevalence of anaplasmosis in both water buffaloes and cattle in Karachi and Sindh; however, all subsequent studies from Karachi and environs (i.e., Hyderabad) as well as other parts of the country have reported lower prevalences (9-22\%) (Table 4), which appear to be within the expected range for endemic regions. Recently, using the molecular detection methods, Ashraf et al. [57] reported a considerably higher prevalence (41.0 \%) of Anaplasma species. Bovine anaplasmosis has been found to be higher during the summer season (April to September) in exotic breeds of cattle, the Kundi breed of water buffalo, female animals, and small dairy farms [47, 48, 56]. Species of Hyalomma and Rhipicephalus (ticks) have been linked to the transmission of bovine anaplasmosis in Pakistan; however, no information is available either on experimental transmission of the disease using tick vectors or on Anaplasma species in un-engorged, potential tick vectors. Figure 1 and Table 4 
Table 3 List of key studies of bovine Babesia/babesiosis in Pakistan

\begin{tabular}{|c|c|c|c|c|c|c|c|c|}
\hline \multirow{2}{*}{$\begin{array}{l}\text { Pathogen } \\
\text { (s) } \\
\text { detected }\end{array}$} & \multirow[t]{2}{*}{ Host (s) } & \multirow[t]{2}{*}{ Location (s) } & \multirow[t]{2}{*}{$\begin{array}{l}\text { Study population and sampling } \\
\text { design }\end{array}$} & \multirow[t]{2}{*}{ Sampling period } & \multirow[t]{2}{*}{$\begin{array}{l}\text { Detection } \\
\text { method (s) }\end{array}$} & \multicolumn{2}{|c|}{$\begin{array}{l}\text { Percentage of test positive animals } \\
\text { (proportion) }\end{array}$} & \multirow[t]{2}{*}{ Reference } \\
\hline & & & & & & Cattle & Buffaloes & \\
\hline Babesia sp. & $\begin{array}{l}\text { Buffaloes, cattle (local } \\
\text { breeds) }\end{array}$ & Karachi & $\begin{array}{l}\text { Healthy animals slaughtered } \\
\text { in abattoir; convenient }\end{array}$ & Sep 1984 to Feb 1985 & Blood smear & $4.2(4 / 95)$ & $1.4(3 / 219)$ & [51] \\
\hline Babesia sp. & $\begin{array}{l}\text { Buffaloes, cattle (local } \\
\text { breeds) }\end{array}$ & Hyderabad & $\begin{array}{l}\text { Healthy animals from local } \\
\text { private dairy farms; convenient }\end{array}$ & Oct 1990 to Dec 1991 & Blood smear & $1(1 / 100)$ & $1(1 / 100)$ & {$[40]$} \\
\hline Babesia sp. & $\begin{array}{l}\text { Buffaloes, cattle (local } \\
\text { and exotic breeds) }\end{array}$ & Attock, Islamabad & $\begin{array}{l}\text { Healthy animals from public } \\
\text { livestock farms; convenient }\end{array}$ & Sep 1999 to May 2001 & Blood smear & $0.65(2 / 307)$ & $0(0 / 155)$ & [41] \\
\hline B. bigemina & \multirow[t]{2}{*}{ Cattle (local breeds) } & \multirow[t]{2}{*}{ Peshawar } & \multirow{2}{*}{$\begin{array}{l}\text { Healthy animals from local } \\
\text { private dairy farms; convenient }\end{array}$} & \multirow[t]{2}{*}{2001} & \multirow[t]{2}{*}{ Blood smear } & ${ }^{1} B b i: 1.75(5 / 285)$ & \multirow[t]{2}{*}{ Not applicable (NA) } & \multirow[t]{2}{*}[42]{} \\
\hline B. bovis & & & & & & ${ }^{2} B b o: 2.80(8 / 285)$ & & \\
\hline \multirow[t]{2}{*}{ Babesia sp. } & \multirow{2}{*}{$\begin{array}{l}\text { Cattle (Friesian and } \\
\text { Jersey) }\end{array}$} & \multirow[t]{2}{*}{ Kasur } & \multirow{2}{*}{$\begin{array}{l}\text { Healthy animals from a public } \\
\text { livestock farm; convenient }\end{array}$} & \multirow[t]{2}{*}{ Jul 2003 to Jun 2004} & \multirow[t]{2}{*}{ Blood smear } & Holstein: 2.5 (5/200) & \multirow[t]{2}{*}{ NA } & \multirow[t]{2}{*}{ [43] } \\
\hline & & & & & & Jersey: 2.5 (5/200) & & \\
\hline B. bigemina & Cattle (local breeds) & Malakand Agency & $\begin{array}{l}\text { Healthy animals from local } \\
\text { private dairy farms; convenient }\end{array}$ & - & Blood smear & $5.2(42 / 794)$ & NA & {$[52]$} \\
\hline Babesia sp. & $\begin{array}{l}\text { Cattle (local and exotic } \\
\text { breeds) }\end{array}$ & Malakand Agency & $\begin{array}{l}\text { Healthy animals from local } \\
\text { private dairy farms; convenient }\end{array}$ & - & Blood smear & $6.6(73 / 1100)$ & NA & [53] \\
\hline B. bigemina & \multirow[t]{2}{*}{ Friesian cattle } & \multirow[t]{2}{*}{ Kasur } & \multirow[t]{2}{*}{$\begin{array}{l}\text { Healthy animals from local } \\
\text { private dairy farms; convenient }\end{array}$} & \multirow[t]{2}{*}{ - } & \multirow{2}{*}{$\begin{array}{l}\text { Blood smear, } \\
\text { PCR }\end{array}$} & $\begin{array}{l}{ }^{3} \mathrm{BS}: \mathrm{Bbi}=6(6 / 100) \\
B b 0=3(3 / 100)\end{array}$ & \multirow[t]{2}{*}{ NA } & \multirow[t]{2}{*}{ [7] } \\
\hline B. bovis & & & & & & $\begin{array}{l}{ }^{4} \mathrm{PCR}: \mathrm{Bbi}=13(13 / 100) \\
\mathrm{Bbo}=7(7 / 100)\end{array}$ & & \\
\hline Babesia sp. & Cattle (cross-bred calves) & Sahiwal & $\begin{array}{l}\text { Healthy animals from a public } \\
\text { livestock and local private dairy } \\
\text { farms; convenient }\end{array}$ & May to Jul 2005 & Blood smear & $7.2(30 / 415)$ & NA & {$[54]$} \\
\hline B. bigemina & \multirow[t]{2}{*}{ Cattle (cross-bred) } & \multirow[t]{2}{*}{ Sahiwal } & Healthy animals from a public & Jun to Aug 2005 & Blood smear, PCR & BS: $18(18 / 100)$ & NA & [49] \\
\hline B. bovis & & & k farm; con & & & $\begin{array}{l}\text { PCR: } 29(29 / 100) ; B b i=18 \\
(18 / 100) ; B b o=11(11 / 100)\end{array}$ & & \\
\hline B. bovis & Buffaloes, cattle (local & Bahawalnagar, Bhakar, & Healthy animals from local & Jan to Aug 2010 & Blood smear, PCR & BS: 2.7 (4/144) & PCR: 23.1 (9/39) & {$[50]$} \\
\hline & & $\begin{array}{l}\text { Layyah, Multan, } \\
\text { Muzaffar Garh, Vehari }\end{array}$ & private darry farms; conver & & & PCR: 17.1 (18/105) & & \\
\hline B. bovis & Buffaloes & Karachi & $\begin{array}{l}\text { Healthy animals from the } \\
\text { Landhi Dairy Colony; } \\
\text { convenient }\end{array}$ & Apr to Oct 2011 & Blood smear & N/A & $3(3 / 100)$ & {$[46]$} \\
\hline B. bigemina & Cattle (local and exotic & Sargodha & Healthy animals from local & Aug 2008 to Jul 2009 & Blood smear & $6.57(23 / 350)$ & NA & {$[47]$} \\
\hline & & & $\begin{array}{l}\text { private dairy farms; multi-stage } \\
\text { cluster random }\end{array}$ & & & ${ }^{5}$ Mixed: $1.7(6 / 350)$ & & \\
\hline B. bigemina & $\begin{array}{l}\text { Cattle (local and exotic } \\
\text { breeds) }\end{array}$ & $\begin{array}{l}\text { Khushab, Rawalpindi, } \\
\text { Sargodha }\end{array}$ & $\begin{array}{l}\text { Healthy animals from local } \\
\text { private dairy farms; convenient }\end{array}$ & Sep 2009 to Aug 2010 & Blood smear & $4.8(50 / 1050)$ & NA & {$[48]$} \\
\hline B. bigemina & Cattle (local breeds) & Charsadda, Swabi & Healthy animals from local & Jan 2010 to Dec 2011 & Blood smear & $B b i=19(19 / 100) ;$ & NA & {$[55]$} \\
\hline B. bovis & & & & & & & & \\
\hline
\end{tabular}

${ }^{1}$ Babesia bigemina; ${ }^{2}$ Babesia bovis; ${ }^{3}$ Blood smear; ${ }^{4}$ Polymerase chain reaction; ${ }^{5}$ Mixed infection of B. bigemina with either A. marginale or T. annulata; - denotes lack of information 
Table 4 List of key studies of bovine Anaplasma/anaplasmosis in Pakistan

\begin{tabular}{|c|c|c|c|c|c|c|c|c|}
\hline \multirow[t]{2}{*}{ Pathogen (s) detected } & \multirow[t]{2}{*}{ Host (s) } & \multirow[t]{2}{*}{ Location (s) } & \multirow[t]{2}{*}{$\begin{array}{l}\text { Study population and } \\
\text { sampling design }\end{array}$} & \multirow[t]{2}{*}{ Sampling period } & \multirow[t]{2}{*}{$\begin{array}{l}\text { Detection } \\
\text { method (s) }\end{array}$} & \multicolumn{2}{|c|}{$\begin{array}{l}\text { Percentage of test positive } \\
\text { animals (proportion) }\end{array}$} & \multirow[t]{2}{*}{ Reference } \\
\hline & & & & & & Cattle & Buffaloes & \\
\hline Anaplasma marginale & $\begin{array}{l}\text { Buffaloes, cattle (local } \\
\text { breeds) }\end{array}$ & Karachi & $\begin{array}{l}\text { Animals slaughtered in } \\
\text { abattoir; convenient }\end{array}$ & Nov 1984 to Dec 1985 & Blood smear & $60(30 / 50)$ & $60(60 / 100)$ & [8] \\
\hline A. marginale & \multirow{2}{*}{$\begin{array}{l}\text { Buffaloes, cattle (local } \\
\text { breeds) }\end{array}$} & \multirow[t]{2}{*}{ Hyderabad } & \multirow{2}{*}{$\begin{array}{l}\text { Healthy animals from } \\
\text { local private dairy farms; } \\
\text { convenient }\end{array}$} & \multirow[t]{2}{*}{ Oct 1990 to Dec 1991} & \multirow[t]{2}{*}{ Blood smear } & ${ }^{1}$ Am: 11 (11/100) & Am: 19 (19/100) & \multirow[t]{2}{*}[40]{} \\
\hline A. centrale & & & & & & ${ }^{2} A c: 7(7 / 100)$ & AC: $11(11 / 100)$ & \\
\hline A. marginale & $\begin{array}{l}\text { Buffaloes, cattle (local } \\
\text { and exotic breeds) }\end{array}$ & Attock, Islamabad & $\begin{array}{l}\text { Healthy animals from } \\
\text { public livestock farms; } \\
\text { convenient }\end{array}$ & Sep 1999 to May 2001 & Blood smear & $17.3(53 / 307)$ & $12.9(20 / 155)$ & [41] \\
\hline A. marginale & \multirow[t]{3}{*}{ Cattle (local breeds) } & \multirow[t]{3}{*}{ Peshawar } & \multirow{3}{*}{$\begin{array}{l}\text { Healthy animals from } \\
\text { local private dairy farms; } \\
\text { convenient }\end{array}$} & \multirow[t]{3}{*}{2001} & \multirow[t]{3}{*}{ Blood smear } & Am: $4.2(12 / 285)$ & \multirow[t]{3}{*}{ Not applicable (NA) } & \multirow[t]{3}{*}{ [42] } \\
\hline \multirow[t]{2}{*}{ A. centrale } & & & & & & Ac: $3.86(11 / 285)$ & & \\
\hline & & & & & & ${ }^{3}$ Mixed: 4.21 (12/285) & & \\
\hline A. marginale & \multirow{3}{*}{$\begin{array}{l}\text { Buffaloes, cattle (local } \\
\text { breeds) }\end{array}$} & \multirow[t]{3}{*}{ Hyderabad } & \multirow{3}{*}{$\begin{array}{l}\text { Healthy animals from } \\
\text { local private dairy farms; } \\
\text { convenient }\end{array}$} & \multirow[t]{3}{*}{ Feb to Apr 2004} & \multirow[t]{3}{*}{ Blood smear } & Am: 22 (55/250) & Am: $13.6(34 / 250)$ & \multirow[t]{3}{*}[58]{} \\
\hline \multirow[t]{2}{*}{ A. centrale } & & & & & & Ac: $9.2(23 / 250)$ & Ac: $8.4(21 / 250)$ & \\
\hline & & & & & & Mixed: 20.8 (52/250) & Mixed: 8 (20/250) & \\
\hline A. marginale & Buffaloes, cattle & $\begin{array}{l}\text { Different districts of } \\
\text { Khyber Pakhtunkhwa }\end{array}$ & $\begin{array}{l}\text { Healthy animals from } \\
\text { local private dairy farms; } \\
\text { convenient }\end{array}$ & Jun to Jul 2003 & Blood smear & $15.1(8 / 53)$ & $26.1(17 / 65)$ & {$[59]$} \\
\hline \multirow[t]{2}{*}{ A. marginale } & \multirow{2}{*}{$\begin{array}{l}\text { Cattle (local and exotic } \\
\text { breeds) }\end{array}$} & \multirow[t]{2}{*}{ Sargodha } & \multirow{2}{*}{$\begin{array}{l}\text { Healthy animals from } \\
\text { local private dairy farms; } \\
\text { multi-stage cluster } \\
\text { random }\end{array}$} & \multirow[t]{2}{*}{ Aug 2008 to Jul 2009} & Blood smear & $9.7(34 / 350)$ & $\mathrm{N} / \mathrm{A}$ & [47] \\
\hline & & & & & & ${ }^{4}$ Mixed: 3.1 (11/350) & & \\
\hline A. marginale & $\begin{array}{l}\text { Cattle (local and exotic } \\
\text { breeds) }\end{array}$ & $\begin{array}{l}\text { Khushab, Rawalpindi, } \\
\text { Sargodha }\end{array}$ & $\begin{array}{l}\text { Healthy animals from } \\
\text { local private dairy farms; } \\
\text { convenient }\end{array}$ & Sep 2009 to Aug 2010 & Blood smear & $5.8(61 / 1050)$ & N/A & [48] \\
\hline A. marginale & Buffaloes & Karachi & $\begin{array}{l}\text { Healthy animals from } \\
\text { the Landhi Dairy Colony; } \\
\text { convenient }\end{array}$ & Apr to Oct 2011 & Blood smear & N/A & $9(9 / 100)$ & {$[46]$} \\
\hline Anaplasma sp. & Buffaloes & Bahawalnagar, Burewala, & Healthy animals from & May to Sep 2001 & ${ }^{5} \mathrm{PCR}-\mathrm{RFLP}$ & NA & Anaplasma sp. & {$[57]$} \\
\hline A. marginale & & $\begin{array}{l}\text { Kohat, Layyah, Multan, } \\
\text { Peshawar }\end{array}$ & $\begin{array}{l}\text { local private dairy farms; } \\
\text { random }\end{array}$ & & & & $41(115 / 281)$ & \\
\hline & & & & & & & Am: $17(20 / 155)$ & \\
\hline A. marginale & $\begin{array}{l}\text { Cattle (local and exotic } \\
\text { breeds) }\end{array}$ & $\begin{array}{l}\text { Khushab, Rawalpindi, } \\
\text { Sargodha }\end{array}$ & $\begin{array}{l}\text { Healthy animals from } \\
\text { local private dairy farms; } \\
\text { convenient }\end{array}$ & Sep 2009 to Aug 2010 & Serology - ${ }^{6}$ ELISA & - & N/A & {$[60]$} \\
\hline Anaplasma sp. & $\begin{array}{l}\text { Buffaloes, cattle (local } \\
\text { and exotic breeds) }\end{array}$ & Khanewal & $\begin{array}{l}\text { Healthy animals from } \\
\text { local private dairy farms; } \\
\text { simple random }\end{array}$ & May 2011 to April 2012 & Blood smear & $4.1(34 / 836)$ & $4.29(30 / 700)$ & {$[56]$} \\
\hline
\end{tabular}


show the locations of anaplasmosis, according to studies conducted thus far in Pakistan; almost all of these studies were carried out around major veterinary research institutions or near public livestock research stations, suggesting a sampling bias. Furthermore, convenient sampling seems to be another source of bias in all published studies, except those by Ali et al. [48] and Sajid et al. [56] who specified the sampling design of their study (see Table 4).

\section{Methods currently used in Pakistan for the diagnosis of TBDs}

Presently, a number of approaches are being used for the diagnosis of TBDs and for studying their epidemiology. For example, clinical signs, and the detection of pathogens on stained blood smears (e.g., demonstration of Anaplasma spp. as inclusion-bodies within erythrocytes, Babesia, and Theileria spp. as piroplasms within erythrocytes, and Theileria spp. as schizonts within leucocytes) or smears of lymph node biopsies (for Theileria spp.) have been the most commonly used diagnostic methods (see Tables 23 and 4). In addition, a number of serological tests have been used in epidemiological surveys of different TBDs; they include a competitive enzyme-linked immunosorbent assay (cELISA) using the MSP-5 antigen [61] and an indirect immunofluorescence antibody technique (IFAT; [62]) for Anaplasma spp., and ELISA, and IFAT for Babesia spp. [18] as well as Theileria spp. [63, 64]. Although various polymerase chain reaction (PCR) techniques have been developed for anaplasmosis, babesiosis [61, 65-68] and tropical theileriosis [69-71] in different laboratories around the world, these methods are not yet routinely used for surveys in developing countries such as Pakistan, possibly due to the relatively high cost of reagents and/or the expertise required to perform these assays.

In Pakistan, almost all of the studies reporting bovine TBDs have used the stained blood smear as a diagnostic method (see Tables 23 and 4), and only a few studies, in recent years, have utilized PCR for the detection of T. annulata [7, 32, 35-37], Babesia spp. [7, 49, 50] and Anaplasma spp. [57]. In addition, Atif et al. [60] used, for the first time, a serological assay to estimate the prevalence of Anaplasma infection or exposure in cattle in Pakistan using the MSP-5 cELISA, although, surprisingly, these authors did not mention the overall seroprevalence in their paper. In addition to the use of conventional and modern diagnostic methods, a number of studies reported the haematological and biochemical status of water buffaloes and cattle clinically affected by theileriosis, babesiosis, and anaplasmosis [36, 37, 44, 45, 48, 52, 53, 72, 73]. For instance, Durrani et al. [44] reported a significant decrease in packed cell volume (PCV), total erythrocyte count (TEC), and haemoglobin $(\mathrm{Hb})$ concentration in water buffaloes suffering from tropical theileriosis. Similarly, Qayyum et al. [45] studied the haematological profiles in exotic and cross-bred cattle with clinical signs consistent with theileriosis, and found a significant decrease in the mean values of PCV, TEC, $\mathrm{Hb}$, and total leukocyte count (TLC) in diseased compared with healthy cattle. Recently, Khan et al. [73] investigated haematological and biochemical changes associated with bovine theileriosis in cross-bred cows, and found significant changes in concentrations of total serum protein, globulins, albumin, phosphorus, calcium, triglycerides, cholesterol, alanine transaminase activity, and serum bilirubin.

\section{Prevention and control of TBDs in Pakistan}

Currently, a number of methods, including chemical tick control, chemotherapy as well as prophylaxis and/or vaccination are used worldwide to reduce economic losses resulting from TBDs in bovines [74]. Although tick control has been the most commonly used method of controlling these TBDs, the reliance on chemicals is decreasing due to the possible emergence of acaricideresistant ticks [75] as well as public health concerns about residues in meat and milk [76, 77].

A number of studies have tested the efficacy of various drugs (individually or in combination with antibiotics) for the treatment or prophylaxis of theileriosis, babesiosis, and anaplasmosis using buparvaquone, diminazene aceturate + imidocarb dipropionate and oxytetracycline, respectively [38, 43, 45, 54, 78]. Owing to limited understanding of bovine TBDs, currently, no schedule for the chemoprophylaxis of these is in place in Pakistan. For tick control, grooming is the most commonly used strategy, particularly at small-holding farms. In Pakistan, grooming involves the manual removal of ticks and burning them on the fire made with cattle dung cakes, which is also a common tick control strategy in other developing countries $[79,80]$. Another method to treat and/or control ticks is spraying the animals and their surroundings with cypermethrine during high-risk months (May to September) of the year. Recently, with the establishment of large commercial dairy farms, a number of acaricides, such as macrocyclic lactones (Tariq Abbas, personal communications), are also being used to control ticks on water buffaloes and cattle in Pakistan.

\section{Conclusions and future scope}

Most previous studies of bovine anaplasmosis, babesiosis, and theileriosis in Pakistan have (i) estimated the prevalence of these TBDs in one or more districts around major veterinary research institutions or on public livestock research stations using conventional diagnostic methods, (ii) evaluated the efficacy of various drugs against these diseases, or (iii) assessed changes in haematological and 
biochemical parameters in water buffaloes and cattle affected by these three TBDs. Although epidemiological studies have provided some insight, the interpretations from various investigations are compromised because of limitations in study design and the diagnostic methods employed. On one hand, some studies did not consider agro-ecological zones, production system, age structure of the bovine population, sampling strategy and season, or breed, which are all factors that can affect the prevalence of TBDs. On the other hand, in most cases, molecular methods were not used to achieve a genetic identification of the species or genotypes of pathogens present. Therefore, this review indicates that a lack of accurate data on the epidemiology of bovine TBDs and their vectors makes it challenging to assess their economic impact on water buffaloes and cattle production in the different agroecological zones of this country.

Given that the dairy industry is rapidly expanding, nationwide epidemiological surveys should be carried to establish the spatial distribution and economic impact of TBDs and ticks, to guide future research, and control. As published information relates to cattle, future work should focus on estimating the disease impact on the water buffalo, which is the mainstay dairy animal in Pakistan. It will also be important to assess whether water buffaloes and/or other animals (e.g., wildlife) are reservoir hosts for pathogens that are transmissible to cattle, given that $T$. parva infection is known to be asymptomatic in the African buffalo (Syncerus caffer) but causes disease in cattle, leading to significant morbidity, and mortality [81]. Furthermore, as multi-host pathogens (including ticks) are economically important and can cross-transmit between domesticated and wild animals [82], improved control strategies for bovine TBDs of livestock in Pakistan will need to consider findings from future surveys of wildlife for ticks and bloodborne pathogens.

Although various studies have attempted to genetically characterize T. annulata [7, 32, 36, 37], Babesia spp. [7, 49, 50] and Anaplasma spp. [57] based on the presence or size of products produced by PCR, amplicons were not sequenced to verify their specificity and genetic identity. To date, only Khan et al. [35] sequenced nuclear ribosomal DNA (18S and internal transcribed spacer, ITS) regions from $T$. annulata isolates from cattle from two districts in Punjab province; these authors found that some of the T. annulata sequences matched those from Turkey, while others were novel, suggesting a genetic distinctiveness. Therefore, there is a need to focus on exploring the genetic composition of tick-borne pathogens of bovines in Pakistan and assessing disease transmission patterns.

The present review shows clearly that the challenge of studying TBDs in Pakistan relates largely to the limitations of current methods used for the diagnosis of infections and disease. Before large-scale field studies of the epidemiology of TBDs can be undertaken, it will be essential to be able to accurately diagnose, identify, and differentiate the respective pathogens. For future epidemiological studies, it is recommended that specific and sensitive PCR-based tools, such as real-time, or multiplex-tandem PCR [83-86] and/or single-strand conformation polymorphism (SSCP) analysis [87, 88], be used for diagnostic, systematic, and population genetic studies, thereby helping to identify species and genotypes of pathogens.

These or similar tools might be used to specifically explore oriental theileriosis in Pakistan. Although $T$. orientalis has been detected in India [89] and Sri Lanka [90], it appears not to have been studied or reported from Pakistan. It is possible that autochtonous or introduced infections of $T$. orientalis occur in bovines in this country. For instance, thousands of dairy cattle are imported to Pakistan from the State of Victoria in Australia. Given that there is evidence of recent outbreaks of oriental theileriosis in this state, that T. orientalis is now endemic there [91-93] and that blood samples from cattle are not screened using molecular tools for piroplasms prior to export to Pakistan, it would be important to estimate the prevalence of $T$. orientalis genotypes and their intensity of infection in dairy cattle upon arrival to Pakistan, and, if found, then to track these genotypes and assess whether they spread to local breeds of cattle, water buffaloes and/or other livestock or wildlife.

Although the current control of bovine TBDs in Pakistan relies mainly on tick control using acaricides, no study has yet assessed the status of acaricidal resistance in ticks, as such resistance has been recorded in various countries [75]. In terms of alternative methods of tick and TBD control, once the epidemiological status of the three main bovine TBDs in Pakistan has been studied in some detail, it would be useful to consider assessing the utility of vaccines. Vaccines are available to protect cattle against bovine theileriosis, babesiosis, and anaplasmosis [94]. For instance, a vaccine containing in vitro-attenuated $T$. annulata, and developed in Israel, is currently being used to control tropical theileriosis in China, Iran, Israel, Morocco, Tunisia, and Turkey [94]. Similarly, a live vaccine containing attenuated strains of $B$. bovis and B. bigemina and $A$. marginale was developed in Australia, and has been widely used for the prevention/control babesiosis and anaplasmosis in Argentina, Australia, Israel, South Africa, and some South American countries [94]. As the large-scale production of such vaccines under good manufacturing practice (GMP) is costly, vaccines against local pathogen species and strains might be established manufactured, marketed, and sold 
by government-funded institutions in Pakistan, to ultimately achieve improved, and sustainable control of TBDs in the longer term.

Another possible vaccination strategy to control TBDs could be the use of tick vaccines, which might offer a cost-effective, environmentally friendly alternative to the use of acaricides. For example, the tick vaccine for cattle based on the $R$. microplus Bm86 gut-antigen (TickGARD $^{\circ}$ ) has proved to be effective in Australia and Cuba [94]. Similarly, a vaccine against $H$. anatolicum, a threehost tick vector transmitting $T$. annulata, could also be another alternative [95]. However, the major disadvantage of using tick vaccines is that they will not confer protection against multiple tick species. Nevertheless, the use of a tick vaccine can reduce the acaricidal treatments and a reduction in TBDs [96]. Another alternative strategy that could be explored to control ticks and TBDs in bovines in Pakistan, is the development of tickresistant breeds of cattle. This can be done by crossing the local Pakistani cattle breeds (Bos indicus; relatively resistant to ticks) with high milk-producing exotic cattle breeds (Bos taurus; susceptible to tick infestation) as some studies have noted milk yields in cross-bred animals appear not to be compromised [97, 98].

\section{Competing interests}

The authors declare that they have no competing interests.

\section{Authors' contributions}

AJ conceived the idea, reviewed the literature, and wrote the manuscript with input from all co-authors. TA created the map. All authors read and approved the final manuscript.

\section{Acknowledgements}

This manuscript was prepared for an invited presentation at the International Conference on Advances in Parasitology and Public Health (ICAPPH-2014) at the College of Veterinary and Animal Sciences, Jhang, Pakistan (22-24 October 2014). A travel grant from the Higher Education of Commission, Islamabad, Pakistan to visit Pakistan is gratefully acknowledged (A.J.).

\section{Author details \\ ${ }^{1}$ Faculty of Veterinary and Agricultural Sciences, The University of Melbourne, Werribee, Victoria, Australia. ${ }^{2}$ University College of Veterinary \& Animal Sciences, The Islamia University of Bahawalpur, Punjab, Pakistan. ${ }^{3}$ Department of Parasitology, University of Agriculture, Faisalabad, Punjab, Pakistan. ${ }^{4}$ Department of Zoology, Government College University, Faisalabad, Punjab, Pakistan. ${ }^{5}$ College of Veterinary and Animal Sciences, University College of Veterinary and Animal Sciences, Jhang, Punjab, Pakistan.}

Received: 1 April 2015 Accepted: 11 May 2015

Published online: 22 May 2015

\section{References}

1. Pakistan Economic Survey 2013-14. Ministry of Finance, Islamabad: Government of Pakistan; 2014:23-41.

2. FAO, Zia U, Mahmood T, Ali MR. Dairy Development in Pakistan. Rome: FAO; 2011.

3. Wynn P, Harris D, Moss R, Clem B, Sutton R, Doyle P. Report on dairy mission to Pakistan. mission carried out under the auspices of the AustraliaPakistan agriculture sector linkages program Canberra, Australia, 2006; p. 6.

4. de Castro JJ. Sustainable tick and tickborne disease control in livestock improvement in developing countries. Vet Parasitol. 1997;71:77-97.

5. Perry BD, Randolph TF, McDermott JJ, Sones KR, Thornton PK. Investing in animal health research to alleviate poverty. Nairobi, Kenya; 2002
6. Jonsson NN. The productivity effects of cattle tick (Boophilus microplus) infestation on cattle, with particular reference to Bos indicus cattle and their crosses. Vet Parasitol. 2006;137:1-10.

7. Durrani AZ, Kamal N. Identification of ticks and detection of blood protozoa in friesian cattle by polmerase chain reacton test and estimation of blood parameters in district Kasur. Pakistan Trop Anim Health Prod. 2008:40:441-7.

8. Haider MJ, Bilqees FM. Anaplasmosis in certain mammals in Karachi and adjoing areas. Proc Parasitol. 1988;6:85-8.

9. Siddiqui EH. Report of Workshop held on December 7-9, 1976. In: Henson JB CM, editor. Theileriosis. Nairobi, Kenya: International Development Research Centre; 1977.

10. Darghouth MA, Preston PM, Bouattour A, Kilani M. Theilerioses. In: Lefevre P-C BJ, Chermette R, Uilenberg G, editors. Infectious and Parasitic Diseases of Livestock: bacterial diseases, fungal diseases, parasitic diseases, vol. 2. Paris, France: Lavoisier; 2010. p. 1839-54.

11. Uilenberg $G$. Theilerial species of domestic livestock. In: Irvin $A D$, Cunningham MP, Young AS, editors. Advances in the control of theileriosis. Netherlands: Martinus Nijoff Publishers; 1981. p. 4-35.

12. Uilenberg G, Mpangala C, McGregor W, Callow LL. Biological differences between African Theileria mutans (Theiler 1906) and two benign species of Theileria of cattle in Australia and Britain. Aust Vet J. 1977;53:271-3.

13. Jongejan F, Musisi FL, Moorhouse PD, Snacken M, Uilenberg G. Theileria taurotragi in Zambia. Vet Q. 1986;8:261-3.

14. Bishop RP, Odongo DO, Mann DJ, Pearson TW, Sugimoto C, Haines LR, et al. Theileria. In: Nene V, Kole C, editors. Genome Mapping and Genomics in Animal-Associated Microbes. Berlin Heidelberg: Springer; 2009.

15. E-F M, Sornicle J. Epizootologie et prophylaxie de la theileriose bovine en Tunisie. Bull Off Int Epiz. 1967;25:151-63.

16. Ouhelli H. Research on the conrol of tropical theielriosis in Morocco. In: Second EEC workshop on orientatation and coordination of reseach on tropical theielriosis. Anand, India: 1991; p. 5.

17. Savic S, Vidic B, Grgic Z, Potkonjak A, Spasojevic L. Emerging vector-borne diseases - incidence through vectors. Front Public Health. 2014;2:267.

18. Figueroa JV, L'Hostis M, Camus E. Bovine babesiosis. In: Lefevre P-C, Blancou J, Chermette R, Uilenberg G, editors. Infectious and Parasitic Diseases of Livestock: bacterial diseases, fungal diseases, parasitic diseases, vol. 2. Paris, France: Lavoisier; 2010. p. 1819-38.

19. Callow LL, McGavin MD. Cerebral babesiosis due to Babesia argentina. Aust Vet J. 1963;39:15-21.

20. Camus E, Uilenberg G. Anaplasmosis. In: Lefevre P-C, Blancou J, Chermette R, Uilenberg G, editors. Infectious and Parasitic Diseases of Livestock: bacterial diseases, fungal diseases, parasitic diseases, vol. 2. Paris, France: Lavoisier; 2010. p. 1247-63.

21. Kocan KM, de la Fuente J, Blouin EF, Garcia-Garcia JC. Anaplasma marginale (Rickettsiales: Anaplasmataceae): recent advances in defining host-pathogen adaptations of a tick-borne rickettsia. Parasitology. 2004;129:5285-300.

22. Shaw RD. Tick control on domestic animals. (i) A brief history of the economic significance of tick infestations. Trop Sci. 1969;1 1:113-9.

23. Jonsson NN, Bock RE, Jorgensen WK. Productivity and health effects of anaplasmosis and babesiosis on Bos indicus cattle and their crosses, and the effects of differing intensity of tick control in Australia. Vet Parasitol. 2008;155:1-9.

24. Jonsson NN, Mayer DG, Matschoss AL, Green PE, Ansell J. Production effects of cattle tick (Boophilus microplus) infestation of high yielding dairy cows. Vet Parasitol. 1998;78:65-77.

25. McLeod R, Kristjanson P. Tick Cost: Economic impact of ticks and TBD to livestock in Africa, Asia and Australia. Nairobi Kenya: International Livestock Research Institute; 1999.

26. Biswas $\mathrm{S}$. Role of veterinarian in the care and management during harvest of skin in livestock species. National Seminar Leather Industry in Today's Perspective 14th and 15th November. Kolkata, India; 2003.

27. Sackett $D$, Holmes P. Assessing the economic cost of endemic disease on the profitability of Australian beef cattle and sheep producers. Final report on project AHW.087. North Sydney, Australia: Meat and Livestock Australia Limited; 2006.

28. Minjauw B, McLeod A. Tick-borne diseases and poverty, The impact of ticks and tick-borne diseases on the livelihood of small scale and marginal livestock owners in India and eastern and southern Africa. DFID Animal Health Programme. UK: Centre for Tropical Veterinary Medicine, University of Edinburgh; 2003. 
29. Durrani AZ, Shakoori AR, Kamal N. Bionomics of Hyalomma ticks in three districts of Punjab. Pakistan J Anim Plant Sci. 2008;18:17-20.

30. Ghosh S, Bansal GC, Gupta SC, Ray D, Khan MQ, Irshad H, et al. Status of tick distribution in Bangladesh. India and Pakistan Parasitol Res. 2007;101:S207-16.

31. Sajid MS, lqbal Z, Khan MN, Muhammad G. Point prevalence of hard ticks (lxodids) infesting domestic ruminants of lower Punjab. Pakistan Int J Agric Biol. 2008;10:349-51.

32. Ali Z, Maqbool A, Muhammad K, Khan MS, Younis M. Prevalence of Theileria annulata infected hard ticks of cattle and buffalo in Punjab. Pakistan J Anim Plant Sci. 2013;23:20-6.

33. Tasawar Z, Nasim S, Lashari MH. The prevalence of ixodid ticks on buffaloes at private animal farm Bibipur. Multan Global Vet. 2014;12:154-7.

34. Durrani AZ, Ahmad M, Ashraf M, Khan MS, Khan JA, Kamal N, et al Prevalence of theileriosis in buffaloes and detection through blood smear examination and polymerase chain reaction test in district Lahore. J Anim Plant Sci. 2008;18:59-62.

35. Khan MK, He L, Hussain A, Azam S, Zhang WJ, Wang LX, et al. Molecular epidemiology of Theileria annulata and identification of 185 rRNA gene and ITS regions sequences variants in apparently healthy buffaloes and cattle in Pakistan. Infect Genet Evol. 2013;13:124-32.

36. Khattak RM, Rabib M, Khan Z, Ishaq M, Hameed H, Taqddus A, et al. A comparison of two different techniques for the detection of blood parasite, Theileria annulata, in cattle from two districts in Khyber Pukhtoonkhwa province (Pakistan). Parasite. 2012;19:91-5.

37. Shahnawaz S, Ali M, Aslam MA, Fatima R, Chaudhry Zl, Hassan MU, et al. A study on the prevalence of a tick-transmitted pathogen, Theileria annulata, and hematological profile of cattle from Southern Punjab (Pakistan). Parasitol Res. 2011;109:1155-60.

38. Muhammad G, Saqib M, Athar M, Khan MZ, Asi MN. Clinico-epidemiological and therapeutic aspects of bovine theileriosis. Pak Vet J. 1999;19:6-71.

39. Ashfaque M, Ajmal M, Ahmad S. An outbreak of theileriosis in cross-bred neonate calves. Pak Vet J. 1983;3:44-6.

40. Buriro SN, Phulan MS, Arijo AH, Memon AB. Incidence of some haemoprotozoans in Bos indicus and Bubalus bubalis in Hyderabad. Pak Vet J. 1994;14:28-9.

41. Khan M, Zahoor A, Jahangir M, Mirza MA. Prevalence of blood parasites in cattle and buffaloes. Pak Vet J. 2004;24:193-4.

42. Afridi ZK, Ahmad I. Incidence of anaplasmosis, babesiosis and theileriosis in dairy cattle in Peshawar (Pakistan). Sarhad J Agri. 2005;21:311-6.

43. Zahid I, Latif M, Baloch K. Incidence and treatment of theileriosis and babesiosis. Pak Vet J. 2005;25:137-9.

44. Durrani A, Kamal N, Khan M. Incidence of theileriosis and estimation of packed cell volume, total erythrocyte count and hemoglobin in buffaloes. J Anim Plant Sci. 2006;16:85-8.

45. Qayyum A, Farooq U, Samad HA, Chauhdry HR. Prevalence, clinicotherapeutic and prophylactic studies on theileriosis in district Sahiwal (Pakistan). J Anim Plant Sci. 2010;20:266-70.

46. Bhutto B, Gadahi JA, Khuhro A, Rajput HM, Bhutto F, Rajput MA, et al. A survey on haemo-protozoan parasites in buffaloes of Landhi Dairy Colony, Karachi-Pakistan. Int J Agro Vet Med Sci. 2012;6:73-6.

47. Atif FA, Khan MS, Iqbal HJ, Arshad GM, Ashraf E, Ullah S. Prevalence of Anaplasma marginale, Babesia bigemina and Theileria annulata infections among cattle in Sargodha District. Pakistan Afr J Agric Res. 2012;7:3302-7.

48. Atif FA, Khan MS, Iabal HJ, Roheen T. Prevalence of tick-borne diseases in Punjab (Pakistan) and hematological profile of Anaplasma marginale infection in indigenous and crossbred cattle. Pak J Sci. 2012;64:11-5.

49. Chaudhry ZI, Suleman M, Younus M, Aslim A. Molecular detection of Babesia bigemina and Babesia bovis in crossbred carrier cattle through PCR. Pak J Zool. 2010;42:201-4.

50. Zulfiqar S, Shahnawaz S, Ali M, Bhutta AM, labal S, Hayat S, et al. Detection of Babesia bovis in blood samples and its effect on the hematological and serum biochemical profile in large ruminants from Southern Punjab. Asian Pacific J Trop Biomed. 2012;2:104-8.

51. Haider MJ, Bilqees FM. Babesiosis in some mammals in Karachi. Proc Parasitol. 1987:3:5-11.

52. Ahmad N, Hashmi HA, Khan SA. Study on ticks and haemoparasitic diseases of local cattle in Malakand Agency. J Anim Plant Sci. 2006;16:82-4.

53. Ahmad N, Hashmi HA. A comparative study on the incidence of ticks and ticks borne diseases on local and crossbred cattle in Malakand agency. J Anim Plant Sci. 2007;17:56-8.
54. Niazi N, Khan MS, Avais M, Khan JA, Pervez K, ljaz M. A study on babesiosis in calves at livestock experimental station Qadirabad and adjacent areas, Sahiwal (Pakistan). Pak J Agric Sci. 2008;45:209-11.

55. Ahmad I, Khawja A, Shams S, Ayaz S, Khan S, Akbar N, et al. Detection of babesiosis and identification of associated ticks in cattle. Int J Bioassays. 2014:3:3195-9.

56. Sajid MS, Siddique RM, Khan SA, lqbal Z, Khan MN. Prevalence and risk factors of anaplasmosis in cattle and buffalo populations of district Khanewal, Punjab. Pakistan Global Vet. 2014;12:146-53.

57. Ashraf QU, Khan AU, Khattak RM, Ali M, Shaikh RS, Ali M, et al. A report on the high prevalence of Anaplasma sp. in buffaloes from two provinces in Pakistan. Ticks Tick-borne Dis. 2013;4:395-8.

58. Rajput Zl, Song-hua HU, Arijo AG, Habib M, Khalid M. Comparative study of Anaplasma parasites in tick carrying buffaloes and cattle. J Zhejiang Uni Sci. 2005;6B:1057-62.

59. Talat K, Khanum T, Hayat A. Studies on mammalian haematozoan parasites of NWFP Pakistan. Pak J Biol Sci. 2005;8:726-9.

60. Atif FA, Khan MS, Muhammad F, Ahmad B. Sero-epidemiological study of Anaplasma marginale among cattle. J Anim Plant Sci. 2013;23:740-4.

61. Torioni De Echaide S, Knowles DP, McGuire TC, Palmer GH, Suarez CE, McElwain TF. Detection of cattle naturally infected with Anaplasma marginale in a region of endemicity by nested PCR and a competitive enzyme-linked immunosorbent assay using recombinant major surface protein 5. J Clin Microbiol. 1998;36:777-82.

62. Goff WL, Johnson WC, Kuttler KL. Development of an indirect fluorescent antibody test, using microfluorometry as a diagnostic test for bovine anaplasmosis. Am J Vet Res. 1985;46:1080-4.

63. Darghouth MA, Sassi L, Gharbi M, Soudani MC, Karoui M, Krichi A. Detection of natural infections with Theileria annulata on calves at first theileriosis season: comparison of the Indirect Fluorescent Antibody Test (IFAT) and blood smears. Arch I'Institut Pasteur Tunis. 2004;81:41-5.

64. Bakheit MA, Schnittger L, Salih DA, Boguslawski K, Beyer D, Fadl M, et al. Application of the recombinant Theileria annulata surface protein in an indirect ELISA for the diagnosis of tropical theileriosis. Parasitol Res. 2004;92:299-302

65. Figueroa JV, Chieves LP, Johnson GS, Buening GM. Multiplex polymerase chain reaction based assay for the detection of Babesia bigemina, Babesia bovis and Anaplasma marginale DNA in bovine blood. Vet Parasitol. 1993:50:69-81.

66. Gale KR, Dimmock CM, Gartside M, Leatch G. Anaplasma marginale: detection of carrier cattle by PCR-ELISA. Int J Parasitol. 1996;26:1103-9.

67. Carelli G, Decaro N, Lorusso A, Elia G, Lorusso E, Mari V, et al. Detection and quantification of Anaplasma marginale DNA in blood samples of cattle by real-time PCR. Vet Parasitol. 2007;124:107-14.

68. Kim C, Iseki H, Herbas MS, Yokoyama N, Suzuki H, Xuan X, et al. Development of TaqMan-based real-time PCR assays for diagnostic detection of Babesia bovis and Babesia bigemina. Am J Trop Med Hyg. 2007;77:837-41.

69. d'Oliveira $C$, van der Weide $M$, Habela MA, Jacquiet $P$, Jongejan F. Detection of Theileria annulata in blood samples of carrier cattle by PCR. J Clin Microbiol. 1995:33:2665-9.

70. Gubbels JM, de Vos AP, van der Weide M, Viseras J, Schouls LM, de Vries E, et al. Simultaneous detection of bovine Theileria and Babesia species by reverse line blot hybridization. J Clin Microbiol. 1999;37:1782-9.

71. Gomes J, Inacio J. Direct detection of Theileria annulata in bovine blood samples using standard and isothermal DNA amplification approaches. Method Mol Biol. 2015;1247:175-82.

72. Ahmad A, Ahmad M, Ahmad R. Studies on the occurrence, clinical features and clinico pathological aspects of theileriosis in buffaloes. Ital J Anim Sci. 2010;6:932-4.

73. Khan IA, Khan A, Hussain A, Riaz A, Aziz A. Hemato-biochemical alterations in cross bred cattle affected with bovine theileriosis in semi arid zone. Pak Vet J. 2011;31:137-40.

74. Muhammad G, Naureen A, Firyal S, Saqib M. Tick control strategies in dairy production medicine. Pak Vet J. 2008;28:43-50.

75. Abbas RZ, Zaman MA, Colwell DD, Gilleard J, Iqbal Z. Acaricide resistance in cattle ticks and approaches to its management: the state of play. Vet Parasitol. 2014;203:6-20.

76. Kay BH, Kemp DH. Vaccines against arthropods. Am J Trop Med Hyg. 1994;50:S87-96.

77. Samish M, Ginsberg H, Glazer I. Biological control of ticks. Parasitology. 2004;129:S389-403. 
78. Atif FA, Khan MS, Khan MA, Ashraf M, Avais M. Chemotherapeutic efficacy of oxytetracycline, enrofloxacin and imidocarb for the elimination of persistent Anaplasma marginale infection in naturally infected sahiwal cattle. Pak J Zool. 2012;44:449-56.

79. Masika PJ, Sonandi A, van Averbeke W. Tick control by small-scale cattle farmers in the central Eastern Cape Province, South Africa. J South African Vet Assoc. 1997;68:45-8.

80. Mondal DB, Sarma K, Saravanan M. Upcoming of the integrated tick control program of ruminants with special emphasis on livestock farming system in India. Ticks Tick-Borne Dis. 2013:4:1-10.

81. Lawrence JA, Perry B, Williamson SM. East Coast feve. In: Coet-zer JAW Tustin RC, editors. Infectious diseases of livestock. Cape Town, South Africa: Oxford University; 2004. p. 448-67.

82. Walker JG, Klein EY, Levin SA. Disease at the wildlife-livestock interface: acaricide use on domestic cattle does not prevent transmission of a tick-borne pathogen with multiple hosts. Vet Parasitol. 2014;199:206-14.

83. Chi Q, Liu Z, Li Y, Yang J, Chen Z, Yue C, et al. Development of a real-time PCR assay for detection and quantification of Anaplasma ovis infection. Transbound Emerg Dis. 2013;60:S2119-24.

84. Chaisi ME, Janssens ME, Vermeiren L, Oosthuizen MC, Collins NE, Geysen D. Evaluation of a real-time PCR test for the detection and discrimination of Theileria species in the African buffalo (Syncerus caffer). PLoS One. 2013;8, e75827.

85. Perera PK, Gasser RB, Firestone SM, Smith L, Roeber F, Jabbar A. Semiquantitative multiplexed tandem PCR for detection and differentiation of four Theileria orientalis genotypes in cattle. J Clin Microbiol. 2015;53:79-87.

86. Perera PK, Gasser RB, Pulford DJ, Stevenson MA, Firestone SM, McFadden AMJ, et al. Comparison of the performance of three PCR assays for the detection and differentiation of Theileria orientalis genotypes. Parasite Vectors. 2015;8:192.

87. Cufos N, Jabbar A, de Carvalho LM, Gasser RB. Mutation scanning-based analysis of Theileria orientalis populations in cattle following an outbreak. Electrophoresis. 2012;33:2036-40.

88. Perera PK, Gasser RB, Anderson GA, Jeffers M, Bell CM, Jabbar A. Epidemiological survey following oriental theileriosis outbreaks in Victoria, Australia, on selected cattle farms. Vet Parasitol. 2013;197:509-21.

89. Aparna M, Ravindran R, Vimalkumar MB, Lakshmanan B, Rameshkumar P, Kumar KG, et al. Molecular characterization of Theileria orientalis causing fatal infection in crossbred adult bovines of South India. Parasitol Int. 2011;60:524-9.

90. Sivakumar T, Kothalawala H, Abeyratne SA, Vimalakumar SC, Meewewa AS, Hadirampela DT, et al. A PCR-based survey of selected Babesia and Theileria parasites in cattle in Sri Lanka. Vet Parasitol. 2012;190:263-7.

91. Perera PK, Gasser RB, Read E, Malmo J, Nguyen H, Nyein S, et al. Use of multiplexed tandem PCR to estimate the prevalence and intensity of Theileria orientalis infections in cattle. Infect Genet Evol. 2015;32:68-73.

92. Perera PK, Gasser RB, Firestone SM, Anderson GA, Malmo J, Davis G, et al. Oriental theileriosis in dairy cows causes a significant milk production loss. Parasit Vectors. 2014;7:73.

93. Perera PK, Gasser RB, Jabbar A. Assessment of sequence variability in a p23 gene region within and among three genotypes of the Theileria orientalis complex from south-eastern Australia. Ticks Tick-borne Dis. 2015;6:123-8.

94. Lightowlers MW. Vaccinations. In: Bowman DD, editor. Georgis' parasitology for veterinarians. Missouri: Saunders; 2013. p. 436-9.

95. Ghosh S, Ray DD, Vanlahmuaka, Das G, Singh NK, Sharma JK, et al. Progress in development of vaccine against Hyalomma anatolicum anatolicum-Indian scenario. Vaccine. 2008;26:G40-7.

96. de la Fuente J, Almazan C, Canales M, de la Lastra JM P, Kocan KM, Willadsen P. A ten-year review of commercial vaccine performance for control of tick infestations on cattle. Anim Health Res Rev. 2007:8:23-8.

97. Jonsson NN, Mayer DG, Green PE. Possible risk factors on Queensland dairy farms for acaricide resistance in cattle tick (Boophilus microplus). Vet Parasitol. 2000;88:79-92.

98. Turner LB, Harrison BE, Bunch RJ, Neto LRP, Li Y, Barendse W. A genome-wide association study of tick burden and milk composition in cattle. Anim Prod Sci. 2010;50:235-45.

\section{Submit your next manuscript to BioMed Central and take full advantage of:}

- Convenient online submission

- Thorough peer review

- No space constraints or color figure charges

- Immediate publication on acceptance

- Inclusion in PubMed, CAS, Scopus and Google Scholar

- Research which is freely available for redistribution 